\title{
QUAN HỆ MỸ-TRUNG DỨ̛́I THỜI TỔNG THỐNG DONALD TRUMP
}

\author{
Nguyễn Ngọc Anh*
}

\author{
Trung tâm Ngôn ngũu và Quốc tế học, Trường Đại học Ngoại ngũu, ĐHQGHN, \\ Phạm Văn Đồng, Cầu Giấy, Hà Nội, Việt Nam \\ Nhận bài ngày 13 tháng 2 năm 2017
}

Chỉnh sửa ngày 23 tháng 3 năm 2017; Chấp nhận đăng ngày 27 tháng 3 năm 2017

Tóm tắt: Nghiên cứu trước tiên trình bày bối cảnh và những dự đoán của học giả thế giới về tương lai quan hệ Mỹ-Trung dưới thời Tổng thống Donald Trump. Tiếp theo, nghiên cứu tham chiếu lý thuyết phân tích chính sách đối ngoại để tiến hành phân tích các dự đoán của giới học giả thế giới. Sau cùng, trên cơ sở phân tích các dự đoán, nghiên cứu đưa ra dự đoán về tương lai quan hệ Mỹ-Trung dưới thời Tổng thống Donald Trump. Nghiên cứu dự đoán rằng quan hệ Mỹ-Trung dưới thời Tổng thống Donald Trump sẽ có những căng thẳng, nhưng sẽ không xảy ra xung đột hoặc biến động lớn. Lập luận chính của nghiên cứu là tất cả các quốc gia đều phải đặt lợi ích quốc gia của mình lên trên tất cả. Trong quan hệ Mỹ-Trung, căng thẳng có thể giúp để bảo vệ lợi ích quốc gia, nhưng xung đột thì sẽ lại làm tổn hại lợi ích quốc gia.

Tù khóa: quan hệ, Mỹ, Trung Quốc, Donald Trump, Tập Cận Bình

\section{Đặt vấn đề}

Sang thế kỷ 21, quan hệ Mỹ-Trung trở thành tâm điểm của cả thế giới và có ý nghĩa rất lớn trong việc định hình cục diện quan hệ quốc tế thế kỷ 21. Năm 2012 sau khi trở thành Tổng Bí thư của Đảng Cộng sản Trung Quốc, Tập Cận Bình đã đề ra chiến lược "Giấc mơ Trung Hoa" nhằm tăng cường quyền lực và nâng cao vị thế của Trung Quốc trên phạm vi toàn cầu. Trong khi đó Tổng thống Mỹ Barack Obama cũng không ngừng thúc đẩy chiến lược "Xoay trục sang Châu Á" nhằm duy trì quyền lực và địa vị của $\mathrm{Mỹ}$. Nhiều học giả tin rằng cuộc cạnh tranh chiến lược Mỹ-Trung đã nghiêng về Trung Quốc. Về tổng thể, quan hệ hai nước là vừa hợp tác vừa cạnh tranh trong nỗ lực kiềm chế để giữ ổn định. Tuy nhiên sau khi Donald Trump đắc cử Tổng thống ${ }^{(1)}$ thì quan

* ĐT: 84-912093346, Email: ngocanh2us@vnu.edu.vn ${ }^{1}$ Bầu cử Tổng thống Mỹ ngày 8 tháng 11 năm 2016 hệ Mỹ-Trung được dự đoán là sẽ có những thay đổi lớn. Tương lai quan hệ Mỹ-Trung sẽ ra sao đã và đang thu hút sự quan tâm của giới nghiên cứu toàn thế giới và đã có những dự báo được đưa ra. Nghiên cứu này ngoài góp phần làm sáng tỏ thêm các dự báo đó, còn đưa ra dự báo riêng về quan hệ MỹTrung dưới thời Tổng thống Donald Trump.

\section{Bối cảnh và những dự đoán về quan hệ Mỹ-Trung dưới thời Tổng thống Donald Trump}

Trên thế giới, sự nổi lên của Nhà nước Hồi giáo tự xưng IS, cuộc chiến ác liệt ở Syria, Anh quốc tách khỏi EU, tranh chấp Biển Đông leo thang căng thẳng, Triều Tiên tăng cường thử vũ khí hạt nhân, chủ nghĩa dân tộc và chủ nghĩa biệt lập có xu hướng gia tăng.....đã khiến cho tình hình quốc tế trong thời gian gần đây diễn biến rất phức tạp, khó lường. 
Tình hình trong nước Mỹ và Trung Quốc đang có những diễn biến khó lường, tiềm ẩn nguy cơ bất ổn. Kinh tế Mỹ tăng trưởng chậm, không ổn định và những vụ khủng bố khiến dân chúng bất mãn. Nước Mỹ vừa trải qua một mùa bầu cử đầy kịch tính. Chiến thắng của Donald Trump và Đảng Cộng hòa đã gây nên chia rẽ sâu sắc trong nội bộ nước Mỹ, tiềm ẩn nguy cơ bất ổn. Trong khi đó ở Trung Quốc, Đại hội của Đảng Cộng sản Trung Quốc quyết định những nhân sự cấp cao nhất của Trung Quốc nhiệm kỳ 2017-2022 đang đến rất gần trong bối cảnh nền kinh tế phát triển chậm lại, ô nhiễm môi trường nghiêm trọng và nạn tham nhũng tràn lan gây ra bất mãn trong dân chúng. Nguồn vốn không ngừng tháo chạy ra nước ngoài và đồng Nhân dân tệ mất giá khiến giới kinh doanh bi quan. Chiến dịch chống tham nhũng "Đả hổ diệt ruồi” vẫn đang gây chia rẽ và gặp nhiều khó khăn. Tóm lại là "Giấc mơ Trung Hoa" vẫn còn đang ngổn ngang và dang dở.

Trong những năm gần đây, quan hệ MỹTrung luôn là tâm điểm của thế giới. Các nghiên cứu chỉ ra rằng "chính sách xoay trục" sang khu vực châu Á-Thái Bình Dương của Mỹ từ cuối năm 2011 là nhằm kiềm chế Trung Quốc, từ đó duy trì vị thế dẫn dắt của Mỹ tại khu vực này. Để trợ giúp cho chiến lược xoay trục, Mỹ đã tích cực thúc đẩy Hiệp định Đối tác xuyên Thái Bình Dương (TPP) mà không có sự tham gia của Trung Quốc, can dự vào tranh chấp biển đảo tại Biển Đông và Biển Hoa Đông, bố trí hệ thống phòng thủ tại Hàn Quốc........ Đáp lại chiến lược của Mỹ, sau khi lên nắm quyền vào năm 2012(2), Tập Cận Bình đã từ bỏ chiến lược "giấu mình chờ thời" của Đặng Tiểu Bình, đề xướng “Giấc mơ Trung

2 Tập Cận Bình được bầu làm Tổng Bí thư tại Đại hội Đại biểu toàn quốc Đảng Cộng sản Trung Quốc lần thứ 17, năm 2012
Hoa" - Công cuộc phục hưng Trung Hoa - để đưa Trung Quốc trở thành cường quốc toàn cầu. Với những bước đi quyết đoán được hậu thuẫn bởi nguồn lực kinh tế dồi dào, tận dụng bối cảnh quốc tế có lợi và sự sa lầy của Mỹ, Trung Quốc đã gia tăng đáng kể quyền lực trên phạm vi toàn cầu bằng cách tăng cường vai trò trong một số định chế quốc tế (Quỹ Tiền tệ Quốc tế, Hội nghị Thượng đỉnh nhóm các nền kinh tế lớn G20) thậm chí là dẫn dắt (Khối những nền kinh tế mới nổi BRICS hay Ngân hàng Đầu tư Cơ sở hạ tầng Châu Á AIIB), bên cạnh đó là những dự án đầu tư, tài trợ trên phạm vi toàn cầu với số vốn rất lớn. B. R. Deepak (2014) nhận định "Ngân hàng Đầu tư cơ sở hạ tầng châu Á (AIIB), Quỹ con đường Tơ lụa (MSR) và Khu vực thương mại tự do châu Á-Thái Bình Dương (FTAAP) đã đặt Trung Quốc vào vị trí trung tâm địa chính trị-kinh tế toàn cầu và điều này đã buộc Mỹ phải tranh giành vai trò lãnh đạo ít nhất là trong khu vực, thậm chí là toàn cầu."

Trong khi đó, dù vẫn đóng vai trò dẫn dắt thế giới, nhưng quyền lực của Mỹ đã bị giảm sút do trì trệ kinh tế và sự thiếu quyết đoán cùng tham vọng quá sức của Chính quyền Obama. Sức mạnh Mỹ bị phân tán cùng lúc cho nhiều mặt trận để giải quyết các vấn đề và chống chọi với các thế lực chống đối trên phạm vi toàn cầu, từ đó tạo nên bối cảnh quốc tế bất lợi cho Mỹ. Trong nước thì chính quyền của Tổng thống Obama để mất niềm tin của người dân dẫn đến việc Đảng Dân chủ đánh mất quyền kiểm soát lưỡng viện quốc hội vào tay Đảng Cộng hòa, vì vậy chính sách xoay trục của Mỹ chưa đạt được kết quả như mong muốn (Rod Lyon, 2015).

Quan hệ Mỹ-Trung trong giai đoạn này luôn trong trạng thái giằng co, đan xen hợp tác và đấu tranh với lợi ích nghiêng về Trung 
Quốc. Tuy nhiên, một sự kiện làm thay đổi suy nghĩ của các nhà nghiên cứu về quan hệ Mỹ-Trung - đó là cuộc bầu cử Tổng thống Mỹ tháng 11 năm 2016 với chiến thắng của trùm bất động sản, thương gia Donald Trump. Donald Trump trở thành Tổng thống thứ 45 của Mỹ và được gọi là "Tổng thống thương gia” (Laura Koran, Ryan Browne, 2016). Các yếu tố như Donald Trump đắc cử, những phát ngôn khi tranh cử của Donald Trump và những sự lựa chọn nhân sự cho chính quyền mới; những ngôn từ trên báo chí chính thống của Trung Quốc về động thái của Donald Trump... đã khiến cho giới học giả đưa ra hai dự đoán ${ }^{(3)}$ khác nhau về quan hệ Mỹ-Trung dưới thời Donald Trump.

Dự đoán thứ nhất (Jin Yinan, cựu Giám đốc Viện nghiên cứu chiến lược tại Đại học Quốc phòng của Quân đội Giải phóng nhân dân Trung Quốc; Ben Shull của tạp chí The Week, Anh Quốc; Boris Martynov, Phó Giám đốc của Viện Mỹ Latin, thuộc Viện hàn lâm khoa học Nga RAS; Giáo sư chính trị Trung Quốc Song Sang-ho của Đại học Ajou University, Hàn Quốc...): Quan hệ Mỹ - Trung sẽ giống như thời Tổng thống Barack Obama là giằng co, đan xen hợp tác đấu tranh và biến động không lớn.

Dự đoán thứ hai (Liu Youfa - cố vấn cao cấp của Trung tâm Nghiên cứu Ân Độ tại Viện Pangoal; Giáo sư Minghao Zhao, thành viên của Ủy ban quốc gia Trung Quốc tại Hội đồng Hợp tác An ninh châu Á - Thái Bình Dương CSCAP; Bonnie Glaser, chuyên gia về Trung Quốc tại trung tâm Nghiên cứu Chiến lược Quốc tế CSIS; David Shambaugh, chuyên gia về chính

\footnotetext{
${ }^{3}$ Hai dự đoán này được tổng hợp từ các dự đoán trong các bài viết khác nhau
}

sách Trung Quốc của trường đại học George Washington, Cố vấn chính phủ Mỹ...): Quan hệ Mỹ-Trung sẽ rất căng thẳng và có những biến động lớn.

Cơ sở của dự đoán thứ nhất gồm: Đảng Cộng hòa ít can dự vấn đề toàn cầu; chủ nghĩa dân túy, bảo hộ và biệt lập của Trump sẽ khiến cho Mỹ rời xa bốn trụ cột của chính sách "tái cân bằng" của Obama: Xây dựng quan hệ đồng minh và đối tác, củng cố các thể chế khu vực, đẩy mạnh hợp tác kinh tế, thúc đẩy dân chủ và nhân quyền (Prashanth Parameswaran, 2016) từ đó có lợi cho Trung Quốc; Donald Trump là thương gia từng có quan hệ làm ăn với Trung Quốc, Trung Quốc có thể thông qua các kênh khác nhau để tiếp cận và tạo lập quan hệ tốt với Trump và gia đình; mối quan hệ Mỹ-Trung phụ thuộc và gắn bó.

Cơ sở của dự đoán thứ hai gồm: Mỹ sẽ áp dụng tư tưởng của Chủ nghĩa Trọng thương để bảo hộ sản xuất trong nước, những rào cản thuế đối với hàng hóa Trung Quốc sẽ được dựng lên; Mỹ sẽ vẫn tiếp tục chính sách kiềm chế Trung Quốc, cứng rắn và quyết liệt hơn nhằm ngăn chặn những hành động gây hấn của Trung Quốc trên Biển Đông và Biển Hoa Đông; đặc biệt là Mỹ có thể có những điều chỉnh trong quan hệ với Đài Loan mà đỉnh điểm là từ bỏ chính sách "Một Trung Quốc"; Mỹ tăng cường hơn các hoạt động quân sự tại các nơi gần Trung Quốc như Nhật Bản và Hàn Quốc; Mỹ sẽ trừng phạt Trung Quốc về an ninh mạng và sở hữu trí tuệ, Trung Quốc sẽ đáp trả quyết liệt.

Có một điểm rất đáng lưu ý là đa số các nhà nghiên cứu của Mỹ và Trung Quốc không lạc quan về quan hệ Mỹ-Trung dưới thời Donald Trump. 
2. Lý thuyết phân tích chính sách đối ngoại với hai dự đoán

\subsection{Hệ thống quốc tế}

Bước sang thế kỷ 21, cả thế giới đã chứng kiến sự tăng tốc của toàn cầu hóa. Sự tăng tốc này một mặt làm gia tăng nhanh chóng nhu cầu hội nhập và tương tác, mặt khác lại làm nảy sinh và sâu sắc thêm các mẫu thuẫn giữa các chủ thể trên phạm vi rộng hơn. Tuy nhiên các chủ thể trong hệ thống quốc tế, bên cạnh quốc gia còn có các chủ thể phi quốc gia (Non-state Actor) như tổ chức quốc tế, công ty xuyên quốc gia, từ đó tạo nên sự đan xen lợi ích giữa nhiều chủ thể khác nhau khiến cho các chủ thể không thể chỉ làm theo ý mình hoặc chỉ nghĩ đến xung đột mà phải điều chỉnh bản thân cho phù hợp hoặc phải hợp tác với nhau (Hoàng Khắc Nam, 2013). Từ đó, vai trò của các thể chế toàn cầu như (Liên Hợp Quốc, Tổ chức Thương mại Thế giới) hay khu vực (Liên minh Châu Âu, Hiệp hội các Quốc gia Đông Nam Á) được tăng cường để bảo đảm ổn định và thúc đẩy sự tương tác giữa các chủ thể. "Các nhà lý thuyết hệ thống cho rằng hệ thống quốc tế có tác động quan trọng lên các quốc gia; môi trường quốc tế ràng buộc và quy định các quốc gia một cách mạnh mẽ" (Helen V. Milner, 2009). Như vậy hệ thống quốc tế tuy theo quan điểm của Chủ nghĩa Hiện thực là vô chính phủ (cấu trúc quyền lực giữa các quốc gia được sắp xếp theo chiều ngang) nhưng theo quan điểm của Chủ nghĩa Tự do thì lại không vô tổ chức, ví dụ: Tổ chức Thương mại Thế giới (WTO) buộc siêu cường số 1 thế giới là Mỹ phải hạ thuế đối với mặt hàng thép của Ấn Độ vào năm 2000; Nghị quyết 1701 của Hội đồng Bảo an Liên Hợp Quốc đã ngăn chặn thành công xung đột Liban Israel năm 2006......

Hệ thống quốc tế là hệ thống phụ thuộc lẫn nhau, các chủ thể khác nhau trong hệ thống vừa có thể bị ảnh hưởng vừa có thể bị tổn thương bởi hành động của các chủ thể khác (Robert Keohane, Joseph Nye, 2001), ví dụ, hành động Trung Quốc tăng cường quân sự hóa ở Biển Đông năm 2016 đã đe dọa chủ quyền lãnh thổ, tự do và an ninh hàng hải đối với một số quốc gia khác; thông tin thị trường lao động Mỹ khởi sắc trong tháng 6 năm 2016 đã khiến cho thị trường chứng khoán chủ chốt toàn cầu tăng điểm ngay tức thì. Từ phân tích này có thể thấy, dự đoán thứ nhất hợp lý hơn dự đoán thứ hai.

Bước sang thế kỷ 21, quan hệ Mỹ - Trung đã trở thành tâm điểm của thế giới, cựu Ngoại trưởng Mỹ John Kerry (2014) đã thừa nhận quan hệ Mỹ - Trung có tính nhân-quả nhất trên thế giới ngày nay, vì vậy cần được quản lý hết sức cẩn thận và quan hệ này là nhân tố quan trọng nhất định hình thế kỷ 21. Sự hợp tác Mỹ-Trung cần thiết cho sự ổn định và phát triển toàn cầu như chống khủng bố, ngăn ngừa phổ biến vũ khí hạt nhân, ứng phó với biến đổi khí hậu và khủng hoảng tài chính và tăng cường vai trò của các thể chế quốc tế. Hơn nữa, xét từ góc độ quyền lực, cán cân quyền lực Mỹ-Trung cũng không còn quá nghiêng về Mỹ. Xét từ góc độ kinh tế, Mỹ và Trung Quốc là hai nền kinh tế lớn nhất thế giới. Trung Quốc là chủ nợ hàng đầu của $M \tilde{y}^{(4)}, M y ̃$ là nhà nhập khẩu lớn nhất của Trung Quốc. Hai nền kinh tế lớn này có sự phụ thuộc vào nhau rất chặt chẽ, nhất cử nhất động của hai nền kinh tế này đều ảnh hưởng đến kinh tế toàn cầu. Xét từ góc độ quân sự, Mỹ là cường quốc quân sự số 1 thế giới với hệ hống các liên minh quân sự rộng khắp toàn cầu và được xem là "cảnh sát" toàn cầu. Dù tiềm lực quân sự của Trung Quốc không bằng Mỹ, Trung

\footnotetext{
${ }^{4}$ Theo Bloomberg, Nhật Bản đã có thời điểm thay thế Trung Quốc trở thành chủ nợ lớn nhất của Mỹ.
} 
Quốc cũng không có hệ thống các liên minh quân sự như Mỹ $\tilde{y}^{(5)}$, nhưng với tiềm lực quân sự hiện có, Trung Quốc vẫn có đủ sức để tạo ra mối răn đe sống còn đối với Mỹ nếu xảy ra xung đột. Một cuộc chiến Mỹ-Trung sẽ là thảm họa không chỉ đối với hai nước mà là toàn cầu (Rand Corporation, 2016).

Xét theo yếu tố hệ thống, Mỹ hoặc Trung Quốc nếu đơn phương gây căng thẳng một cách phi lý thì sẽ không chỉ bị bên còn lại đáp trả, mà còn bị các thể chế quốc tế và những quốc gia bị ảnh hưởng phản đối. Từ đó dẫn đến chính bản thân mình cũng sẽ bị ảnh hưởng. Nếu Mỹ hoặc Trung Quốc bất chấp các thể chế và các chủ thể trong hệ thống quốc tế để làm theo ý mình, thì hệ thống quốc tế sẽ bị hủy hoại, trật tự thế giới bị đảo lộn, thế giới sẽ rối loạn. Từ đó tạo tiền lệ cho các quốc gia tự làm theo ý mình và hậu quả có thể là "những gì mà Thucydides từng nói kẻ mạnh sẽ làm điều họ muốn; kẻ yếu sẽ phải chịu đựng những gì họ phải chịu.” (Justin Vaisse, 2016).

Với quan niệm truyền thống của Mỹ là Mỹ có vai trò duy trì trật tự thế giới, trong khi đó Trung Quốc cũng ý thức được mình đang trong quá trình trỗi dậy, cả hai sẽ không làm như vậy. Quan hệ Mỹ-Trung có thể có những căng thẳng, nhưng sẽ khó có xung đột hoặc biến động lớn nào xảy ra.

\subsection{Hệ thống chính trị quốc nội}

Đã có những sự tranh luận về ảnh hưởng của hệ thống chính trị quốc nội đối với chính sách đối ngoại của quốc gia, chẳng hạn như Chủ nghĩa Hiện thực tấn công không coi trọng hệ thống chính trị quốc nội nhưng Chủ nghĩa Hiện thực phòng thủ thì lại rất coi trọng hệ

${ }^{5}$ Trung Quốc dù đã có căn cứ quân sự ở 1 quốc gia Châu Phi, những chưa thể xem quốc gia đó là đồng minh quân sự. thống chính trị quốc nội, Chủ nghĩa Hiện thực tân cổ điển hài hòa hơn khi coi trọng cả hệ thống quốc tế và hệ thống chính trị quốc nội (Gideon Rose, 1998).

Trên thực tế ảnh hưởng của hệ thống chính trị quốc nội đến chính sách đối ngoại là không thể phủ định vì chính sách đối ngoại là nhằm để bảo vệ và đạt được các lợi ích quốc gia. Vì vậy nhiều nghiên cứu cho rằng hệ thống chính trị quốc nội là một bộ phận đặc biệt giải thích cho chính sách đối ngoại (James D. Fearon, 1998). Để hiểu được ảnh hưởng này thì cần phải làm rõ cơ chế hoạch định và những yếu tố tác động đến chính sách đối ngoại của Mỹ và Trung Quốc.

Hiến pháp Mỹ không quy định cụ thể việc hoạch định chính sách đối ngoại, nhưng Tổng thống Mỹ dựa vào các ủy ban, bộ, hội đồng thuộc chính phủ để xây dựng và thực thi chính sách đối ngoại, tuy nhiên cần có sự chuẩn thuận (ngân sách, tính hợp pháp) của Quốc hội để chính sách đối ngoại đó có thể thực hiện được (Thomas R. Pickering, 2000). Ngoài ra, Quốc hội Mỹ cũng có thể trực tiếp tham gia vào hoạch định chính sách đối ngoại bằng các luật hay quyết định, chẳng hạn như Quốc hội Mỹ nếu thông qua dự luật trừng phạt Trung Quốc do Thượng nghị sĩ Mỹ Marco Rubio đệ trình "sẽ buộc chính quyền của Tổng thống Donald Trump phải có các biện pháp cứng rắn với Trung Quốc" (Ankit Panda, 2016). Ở quốc gia dân chủ như Mỹ, dư luận công chúng rất quan trọng đối với chính sách đối ngoại. Một chính sách đối ngoại không hợp lòng dân, hậu quả tức thời là những cuộc biểu tình của người dân sẽ tạo nên lực cản rất lớn đối với chính sách đối ngoại, hậu quả sâu xa là người dân Mỹ sẽ bỏ phiếu cho đảng đối lập để hạ bệ đương kim Tổng thống và đảng cầm quyền. Bầu cử là sự quyết định của người dân đối với sự cầm 
quyền của bất cứ chính đảng nào ở Mỹ. The Economist (2016) cho rằng chính Chủ nghĩa dân túy đã giúp Donald Trump trở thành Tổng thống. Điều đặc biệt là dù chưa nhậm chức nhưng vào ngày 12 tháng 1 , Donald Trump đã công bố lập ban vận động tranh cử tổng thống nhiệm kỳ 2. Đây là sự ý thức được sức mạnh của lá phiếu từ người dân $\mathrm{Mỹ}$.

Khác với Mỹ, Trung Quốc là nước Xã hội Chủ nghĩa và chỉ do Đảng Cộng sản cầm quyền ${ }^{(6)}$. Đảng Cộng sản Trung Quốc lãnh đạo toàn diện đất nước Trung Quốc. Vì vậy, dù Bộ Ngoại giao là cơ quan hoạch định chính sách đối ngoại, "nhưng các chính khách trong Thường vụ Bộ Chính trị mới là những người phụ trách chính sách đối ngoại với Hoa Kỳ, Nhật Bản và Đài Loan” (Susan, 2007). Đồng quan điểm này, Jakobson, Manuel (2016) cũng cho rằng "cơ quan quyền lực tối cao có quyền quyết định chính sách đối ngoại của Trung Quốc là Thường vụ Bộ Chính trị Đảng Cộng sản Trung Quốc. Thường vụ Bộ Chính trị quyết định trực tiếp chính sách đối ngoại với Hoa Kỳ, Nhật Bản, Nga và Bắc Triều Tiên.” Ở Trung Quốc, tuy Quốc hội (Đại hội Đại biểu Nhân dân toàn quốc) và Chính phủ (Quốc vụ viện) cũng tham gia vào hoạch định chính sách đối ngoại của Trung Quốc, nhưng người đứng đầu hai cơ quan này đều là thành viên trong Thường vụ Bộ chính trị Đảng Cộng sản Trung Quốc, thậm chí người đứng đầu cơ quan thực thi chính sách đối ngoại (Ngoại trưởng) cũng phải là Ủy viên Trung ương - cấp dưới của Thường vụ Bộ Chính trị. Như vậy, cơ quan quyền lực tối cao quyết định chính sách đối ngoại của Trung Quốc đối với Hoa Kỳ là Thường vụ Bộ chính trị Đảng Cộng sản Trung Quốc. Tuy nhiên, tiếng nói của

${ }^{6}$ Dù ở Trung Quốc có 8 đảng, nhưng Đảng Cộng sản là chấp chính, cầm quyền, 7 đảng còn lại là tham chính, góp ý. người dân được nuôi dưỡng bởi chủ nghĩa dân tộc luôn có tác động không nhỏ đến chính sách đối ngoại của Trung Quốc, đặc biệt là chính sách đối ngoại đối với Mỹ. Theo Susan L. Shirk (2008), "mỗi khi công chúng quan tâm nhiều đến một vấn đề nào đó, giới lãnh đạo lại cảm thấy cần phải hành động cứng rắn để chứng tỏ sự mạnh mẽ của họ. Giống như những trang hảo hán Tàu, họ từ bỏ thái độ trung dung thường thấy trong các vấn đề quốc tế và thể hiện mình như những siêu anh hùng theo chủ nghĩa dân tộc". Một thế lực có ảnh hưởng quan trọng đến chính sách đối ngoại của Trung Quốc là Quân Giải phóng Nhân dân (PLA). PLA có tiếng nói có trọng lượng trong các cơ quan quyền lực của Trung Quốc như “chiếm đa số ghế trong Ban Chấp hành Trung ương (khoảng 22\%) số ủy viên chuyên trách và có 2 đại diện trong số 24 thành viên Bộ Chính trị... khoảng 10\% đại biểu cơ quan lập pháp của Trung Quốc - Quốc hội Nhân dân thuộc giới mặc quân phục" (Susan L. Shirk, 2007) và có thành viên trong Tiểu ban Lãnh đạo Trung ương LSGs, cơ quan được lãnh đạo bởi Tổng Bí thư và chịu trách nhiệm báo cáo với Thường vụ Bộ Chính trị (Linda Jakobson, Ryan Manuel, 2016). PLA "luôn luôn có ảnh hưởng chính trị vì mối quan hệ mật thiết của nó với giới tinh hoa trong Đảng và hào quang chiến thắng của quân đội cách mạng" (Andrew Scobell, 2005), điển hình là Tổng Bí thư Đảng Cộng sản đồng thời là Chủ tịch Quân ủy Trung ương. Tuy nhiên, ảnh hưởng của PLA đến chính sách đối ngoại của Trung Quốc chủ yếu được thể hiện ở vai trò là cơ quan sở hữu sức mạnh quân sự và đảm bảo an ninh quốc gia (Linda Jakobson, Dean Knox, 2010). PLA có những lợi ích riêng, khi an ninh Trung Quốc được cho là bị đe dọa thì lợi ích của PLA sẽ tăng lên, từ đó tạo ra "yếu tố Diều hâu" trong chính sách đối ngoại của Trung Quốc. 
Từ hệ thống chính trị quốc nội Mỹ có thể thấy, Đảng Cộng hòa, với truyền thống (Dennis Prager, 2017) là: Mỹ là lãnh đạo và cảnh sát thế giới, không nước nào được qua mặt; biên giới là một điều tất yếu để định nghĩa và bảo vệ một quốc gia, biên giới là một thứ bất khả xâm phạm; Mỹ là thế lực đạo đức vĩ đại nhất trong tất cả các quốc gia trên thế giới; mối đe dọa lớn nhất đối với thế giới là độc tài, chủ nghĩa Hồi giáo; tăng cường ngân sách quốc phòng, chiến tranh đôi lúc là giải pháp tốt và duy nhất, hòa bình thông qua sức mạnh, vì địch chỉ sợ sức mạnh chứ không sợ lời nói, không giới hạn sức mạnh, quy mô và mục tiêu chiến tranh, sẽ thúc ép chính quyền của Donald Trump cứng rắn với Trung Quốc,, đặc biệt trong tranh chấp lãnh thổ với các nước. Tuy nhiên, do "hai cường quốc đã lệ thuộc vào nhau ở mức độ cao, sự xâm nhập lẫn nhau giữa hai nền kinh tế là rất sâu đậm” (Mark Leonard, 2013), “Trung Quốc cho phép Hoa Kỳ tránh được những nguy cơ ngày càng tăng của tình trạng thiếu tiết kiệm, chính sách tài khóa thiếu thận trọng, và tăng trưởng thu nhập hộ gia đình yếu" (Stephan S. Roach, 2015). Nếu căng thẳng đến mức xung đột làm ảnh hưởng lớn đến chính nước Mỹ thì dư luận và các nhóm lợi ích tại Mỹ sẽ không để yên. Hơn nữa, "Mỹ cũng nên khôn ngoan chấp nhận thực tế rằng thế giới đang thay đổi" (Jim O'Neill, 2015). Vì vậy, Mỹ tăng cường các hành động gây căng thẳng là có thể những sẽ không để xảy ra xung đột quy mô lớn giữa Mỹ và Trung Quốc.

Trong khi đó ở Trung Quốc, mục đích tối cao của chính sách đối ngoại Trung Quốc là duy trì quyền lực của Đảng Cộng sản Trung Quốc (Merriden Varrall, 2015). Chủ nghĩa dân tộc trong dân chúng và thế lực quân đội ở Trung Quốc cũng sẽ thúc ép lãnh đạo Đảng Cộng sản Trung Quốc phải cứng rắn và quyết liệt với Mỹ, đặc biệt trong vấn đề tranh chấp lãnh thổ và Đài Loan. Nếu Mỹ đi quá xa trong vấn đề tranh chấp lãnh thổ và vấn đề Đài Loan, Trung Quốc sẽ đáp trả, sẽ có biến động lớn như dự đoán thứ hai. Nếu Mỹ cứng rắn trong vấn đề thương mại, nền kinh tế phụ thuộc vào xuất khẩu của Trung Quốc sẽ suy giảm. Đảng Cộng sản Trung Quốc phải đối mặt với sự bất mãn của dân chúng và sự thúc ép của các tập đoàn, công ty xuất khẩu. Khi đó, Trung Quốc sẽ có các biện pháp đáp trả, quan hệ hai bên sẽ căng thẳng. Tuy nhiên, "Hoa Kỳ cung cấp cho Trung Quốc cả sự ổn định và động lực tăng trưởng" (Stephan S. Roach, 2015) nên Trung Quốc sẽ có những giải pháp điều chỉnh theo hướng ít nhiều nhượng bộ để tránh căng thẳng leo thang mất kiểm soát gây bất lợi nhiều hơn cho Trung Quốc. Biến động lớn như dự đoán thứ hai vì vậy sẽ không xảy ra.

\subsection{Cá nhân Donald Trump và Tập Cận Bình}

Kinh nghiệm là cơ sở đầu tiên cho việc lựa chọn các quyết sách đối ngoại

Donald Trump có rất ít kinh nghiệm chính trường (Zachary Crockett, 2017), thậm chí không có chút kinh nghiệm ngoại giao quốc tế nào (Latika Bourke, 2016). Tuy nhiên, tính đến khi nhậm chức Tổng thống, Donald Trump lại có khoảng 50 năm kinh nghiệm thương trường. Dù 6 lần phá sản, nhưng Donald Trump vẫn thành công với khối tài sản 3,7 tỷ USD (Forbes, 2016).

Khác với Donald Trump, Tập Cận Bình làm chính trị từ năm 21 tuổi (Tóm tắt tiểu sử đồng chí Tập Cận Bình, 2013). Sau khi kinh qua nhiều chức vụ trong Đảng, chính quyền và quân đội ở các cấp từ địa phương đến trung ương, ở cả 4 miền Đông (Thượng Hải), Tây (Thiểm Tây), Nam (Phúc Kiến), Bắc (Hà Bắc), năm 2012, Tập Cận Bình trở thành lãnh đạo tối cao của Trung Quốc. Tính đến năm 2017, Tập Cận Bình có 45 năm làm chính 
trị, vì vậy, sẽ có rất nhiều kinh nghiệm. Một số chuyên gia cho rằng Tập Cận Bình còn có kinh nghiệm về kinh tế. Trên thực tế, từ khi Tập Cận Bình trở thành lãnh đạo tối cao, kinh tế Trung Quốc đã xảy ra những biến cố lớn như thị trường chứng khoán sụt giảm (2015), năm 2016 đồng Nhân dân tệ mất giá mạnh dẫn đến sự tháo chạy của 1000 tỷ USD vốn đầu tư (Bloomberg, 2016) và tốc độ tăng trưởng kinh tế năm 2015 thấp nhất 25 năm ... Hiện chưa có minh chứng cho kinh nghiệm hoặc thành công của Tập Cận Bình trong lĩnh vực kinh tế.

Tham vọng quyền lực là động lục cho việc lựa chọn các quyết sách đối ngoại

“Giấc mơ Trung Hoa"(7) và "Nước Mỹ vĩ đại trở lại” là biểu hiện tham vọng quyền lực của Tập Cận Bình và Donald Trump.

“Giấc mơ Trung Hoa” không chỉ tạo phúc cho nhân dân Trung Quốc mà còn tạo phúc cho nhân dân thế giới (Tập Cận Bình, 2014). "Giấc mơ Trung Hoa" có “cái lõi là viễn cảnh phục hưng đất nước. Tập (Cận Bình) không giấu giếm tham vọng muốn Trung Quốc có vị trí trung tâm thế giới” (Jeffrey Wasserstrom, 2015), biến Trung Quốc thành “cường quốc lãnh đạo, thậm chí thống trị quan hệ khu vực Châu Á - Thái Bình Dương. Trên thực tế, giống như một fan hâm mộ lịch sử, Tập Cận Bình có thể sẽ nỗ lực khôi phục lại địa vị lịch sử của Trung Quốc trong hệ thống Đông Á hiện đại như kỷ nguyên của Đế chế Trung Hoa (năm 221 trước CN - năm1911 sau CN)" (Zhangfeng, 2015). Như vậy, Tập Cận Bình sẽ có các quyết sách quyết liệt nhằm cạnh tranh quyền lực với Mỹ, đặc biệt tại khu vực Châu Á.

\footnotetext{
7 “Giấc mơ Trung Hoa” được Tập Cận Bình lần đầu đưa ra vào năm 2013, "Nước Mỹ vĩ đại trở lại” được Donald Trump đưa ra trong chiến dịch tranh cử Tổng thống năm 2016.
}

Trong khi đó, theo nhận xét của George Koo (2016), với chính sách đối ngoại như trong bài phát biểu sau chiến thắng (đối xử công bằng với tất cả, tìm điểm tương đồng, tránh thù địch, tìm kiếm hợp tác, tránh xung đột, từ đó tạo dựng mối quan hệ tốt đẹp với tất cả các quốc gia và hình thành những mối quan hệ vĩ đại), Donald Trump sẽ xem xét lợi hại từ góc độ kinh tế và có thể không theo đuổi chính sách bá chủ thế giới như hai đời Tổng thống tiền nhiệm là George $\mathrm{W}$. Bush và Barack Obama. Các nội dung trong bài phát biểu (The New York Times, 2016) mừng chiến thắng của Donald Trump như: "Tôi không tranh cử chức Tổng thống của thế giới mà tranh cử vào chức Tổng thống Mỹ”, "tôi muốn nói với cộng đồng quốc tế rằng dù chúng tôi luôn đặt lợi ích của Mỹ lên hàng đầu, nhưng chúng tôi sẽ quan hệ tốt với tất cả mọi người” và hành động chỉ trích của Donald Trump đối với Clinton là người của toàn cầu, dường như ủng hộ cho nhận định của George Koo. Như vậy, Donald Trump sẽ tập trung quan tâm đến nội bộ nước Mỹ.

Tính cách cá nhân ảnh hưởng đến thiên hương và cách thức lưa chọn quyết sách đối ngoại

Những biểu hiện như phát ngôn, quyết định và cách làm gây tranh cãi, xóa bỏ hoặc thay đổi những kế hoạch hoặc thể chế vốn có để lập cái mới theo ý mình, không sợ thất bại để vươn lên chiến thắng, dính líu tới 4000 vụ kiện, bao gồm cả đi kiện và bị kiện (USA Today, 2017), biểu lộ cảm xúc vui buồn tức thì, ... cho thấy Donald Trump là người thẳng thắn, mạnh mẽ, quyết liệt, kiên cường, không ngại khiêu khích, va chạm và tranh giành, không ưa gò bó và lề lối, thích được chú ý, nhưng bột phát và khó lường.

Tập Cận Bình là người thâm trầm và sâu sắc, từ phát ngôn đến hành vi đều thâm sâu, thận trọng và kín kẽ nhưng không kém phần 
quyết liệt và quyết đoán. Việc tiến hành những thay đổi lớn đối với những kế hoạch và thể chế vốn có, quyết đoán với các sự vụ quốc tế, tích cực đăng cai, tham gia và đề xuất các nghị trình toàn cầu thể hiện Tập Cận Bình có tính cách mạnh mẽ, muốn được chú ý, không ngại tranh giành va chạm, tuy nhiên "cứng rắn như thép" (Lìa ngó ý vương tơ lòng, tình cảm Lý Quang Diệu với Trung Quốc $\left.{ }^{(8)}, 2015\right)$ và ít biểu lộ cảm xúc, nên cũng rất khó để đoán biết trước.

Nếu xét theo kinh nghiệm thì Donald Trump sẽ ưu tiên lĩnh vực mình có kinh nghiệm hơn là thương mại. Tập Cận Bình cũng sẽ thiên về ưu tiên lĩnh vực mình có kinh nghiệm nhiều hơn là chính trị. Sự khác nhau này có thể là nhân tố quan trọng làm giảm bớt căng thẳng trong quan hệ Mỹ-Trung, đặc biệt là khi Mỹ được lợi về kinh tế, Trung Quốc được lợi về chính trị.

Xét theo tham vọng quyền lực toàn cầu, trước mắt thì Donald Trump có thể có ít hơn Tập Cận Bình, nhưng "Nước Mỹ vĩ đại trở lại" theo truyền thống thì phải gắn với sức mạnh nội tại và quyền lực của Mỹ trên thế giới. Quá trình làm cho nước Mỹ vĩ đại trở lại và truyền thống Mỹ là bá chủ thể giới của Đảng Cộng hòa sẽ khiến Tổng thống Donald Trump hiểu rằng "Nước Mỹ vĩ đại trở lại” ngoài là giàu có hơn thì còn phải là không cho phép quốc gia nào được vượt mặt "cảnh sát toàn cầu". Quan hệ Mỹ-Trung khởi đầu có thể không căng thẳng, nhưng khi hai bên tìm cách tăng cường quyền lực thì căng thẳng sẽ xảy ra.

Xét theo tính cách, nếu thực sự quan tâm đến vấn đề nào trong quan hệ Mỹ-Trung thì Donald Trump có thể sẽ không ngại đưa

${ }^{8}$ Dịch ý của cụm từ 剪不断理还乱李光耀的中国情 结 ra những quyết định quyết liệt, bất ngờ có tính khiêu khích hoặc gây tranh cãi đối với Trung Quốc để tranh giành phần thắng hoặc thu hút sự chú ý. Trong khi đó, Tập Cận Bình với tính cách cứng rắn, thận trọng và thâm sâu sẽ không lùi bước. Những quyết định trả đũa hoặc tấn công sẽ vẫn được đưa ra và âm thầm thực hiện. Quan hệ Mỹ-Trung sẽ căng thẳng hoặc thậm chí là xung đột. Như vậy, từ cấp độ cá nhân có thể thấy, quan hệ Mỹ-Trung dưới thời Donald Trump nhiều khả năng sẽ căng thẳng và không loại trừ khả năng xảy ra xung đột hoặc có biến động lớn.

\section{Tương lai nào cho quan hệ Mỹ-Trung dưới thời Tổng thống Donald Trump?}

Tương lai quan hệ Mỹ-Trung có thể sẽ là tổng hòa của hai dự đoán trên, có căng thẳng nhưng sẽ được điều chỉnh, nhượng bộ để tránh xung đột hoặc biến động lớn.

Nhìn từ cấp độ hệ thống, quan hệ giằng co Mỹ-Trung như thời Tổng thống Obama sẽ làm gia tăng quyền lực của Trung Quốc và giảm sút quyền lực của Mỹ. Cán cân quyền lực và cục diện thế giới sẽ thay đổi theo hướng có lợi cho Trung Quốc. Quyền lực gia tăng sẽ tạo điều kiện cho Trung Quốc thay đổi trật tự và luật lệ vốn có, từ đó khiến nhiều quốc gia gồm cả là đồng minh và không phải là đồng minh của Mỹ (những quốc gia đồng tình với Singapore (G. Allison, R. D. Blackwill, A. Wyne, 2013) là cục diện thế giới do Mỹ dẫn dắt là tốt nhất) cảm thấy bất an, từ đó tạo nên sức ép không nhỏ đối với nước Mỹ.

Ở cấp độ quốc gia, Đảng Cộng hòa đang kiểm soát lưỡng viện Quốc hội Mỹ sẽ khó để quyền lực Mỹ dần chuyển cho Trung Quốc trong thế giằng $\mathrm{co}$, từ đó gây khó khăn cho chính đất nước Mỹ. 
Ở cấp độ cá nhân, với tính cách như đã phân tích ở trên, Tổng thống Donald Trump sẽ không thích và không đủ kiên nhẫn để chơi trò kéo co để rồi mình bị thua thiệt. Tuy nhiên, những cảnh báo về hậu quả của xung đột Mỹ-Trung đối với hệ thống quốc tế nói chung, hai nước Mỹ và Trung Quốc nói riêng sẽ có tác dụng hữu hiệu ngăn ngừa xung đột giữa Mỹ và Trung Quốc.

Chính quyền Donald Trump có thể sẽ quan tâm và quyết liệt hơn trong lĩnh vực an ninh mạng, sở hữu trí tuệ và thương mại với Trung Quốc. Đối với tranh chấp biển đảo và vấn đề Đài Loan, Mỹ có thể cứng rắn hơn, nhưng sẽ có giới hạn để tránh xung đột quân sự với Trung Quốc.

Về phần mình, Trung Quốc ý thức được sự thua kém Mỹ về cả kinh tế và quân sự; nên trong cạnh tranh quyền lực toàn cầu với Mỹ, Trung Quốc sẽ vẫn áp dụng chiến thuật "lùi 1 bước tiến 2 bước". Trung Quốc có thể có những nhượng bộ về thương mại, an ninh mạng và sở hữu trí tuệ. Đối với vấn đề tranh chấp biển đảo và vấn đề Đài Loan, Trung Quốc sẽ thận trọng hơn, thường xuyên có phản ứng thăm dò và áp dụng chiến thuật tùy cơ ứng biến. Nhưng nếu Mỹ lấn tới, Trung Quốc sẽ không nhượng bộ. Một cuộc chiến hoàn toàn có khả năng xảy ra.

Nhìn vào cách bố trí nhân sự thì có thể thấy, Chính phủ của Donald Trump đã có sự chuẩn bị cho phương án căng thẳng và hòa giải. Nếu những nhân vật như Peter Navaro, Rex Tilerson có thể khiến quan hệ Mỹ-Trung căng thẳng, thì Đại sứ Mỹ tại Trung Quốc Terry Branstad, hay con gái của Donald Trump là Ivanka Trump lại có thể giúp giảm bớt căng thẳng(9).

${ }^{9}$ Peter Navaro kịch liệt lên án Trung Quốc trong cuốn "Death by China" (Chết dưới tay Trung Quốc); Rex Tilerson từng có tuyên bố cứng rắn là ngăn không cho Trung Quốc tiếp
Dù không ai biết chắc chắn được những gì sẽ xảy ra trong quan hệ giữa Mỹ và Trung dưới thời Tổng thống Donald Trump, những nhưng có một điều có thể biết trước được là chính quyền hai nước trước khi hành động đều sẽ phải đặt lợi ích quốc gia lên trên hết.

\section{Tài liệu tham khảo}

\section{Tiếng Việt}

Hoàng Khắc Nam (2013). Chủ nghĩa Tự do trong quan hệ quốc tế: Những luận điểm chính và sự đóng góp. Khoa học Xã hội \& Nhân văn, Vol.29, No.1, 17-26

Kiều Oanh (2017). Chưa nhậm chức tổng thống, ông Trump đã chuẩn bị tranh cư nhiệm kỳ 2. Truy cập lúc 10:00 ngày 15/01/2017 tại http://thanhnien.vn/the-gioi/chua-nhamchuc-tong-thong-ong-trump-da-chuan-bitranh-cu-nhiem-ky-2-783247.html

\section{Tiếng Anh}

Andrew Scobell (2005). China's Evolving CivilMilitary Ralations: Creeping Guojiahua. Armed Forces and Society, Vol.31, No.2, 233

Ankit Panda (2016). US Sanctions Against China Over the East and South China Seas: A Serious Proposal? Available through $<\mathrm{http} / / /$ thediplomat.com/2016/12/us-sanctionsagainst-china-over-the-east-and-southchina-seas-a-serious-proposal/>, Accessed 16/01/2017 09:49

B.R Deepark (2014). "One Belt One Road”: China at the center of the Global Geopolitics and Geo-economics. Available through $<\mathrm{http}: / /$ www.southasiaanalysis.org/node/1672>, Accessed 02/01/2017 08:49

Dennis Prager (2017). A Guide to Basic Differences Between Left and Right.

cận các đảo nhân tạo bồi đắp trái phép trên Biển Đông; Đại sứ Mỹ tại Trung Quốc Terry Branstad là bạn lâu năm của Tập Cận Bình; con gái của Donald Trump là Ivanka Trump từng có quan hệ với Trung Quốc và đã đến chúc tết Đại sứ quán Trung Quốc tại Mỹ năm 2017. 
Available through <http://townhall.com/ columnists/dennisprager/2017/01/17/aguide-to-basic-differences-between-leftand-right-n2271475>, Accessed 12/01/2017 $15: 30$

Feng Zhang (2015). Is China ready to resume its imperial glory? Available through $<\mathrm{https}$ :// www.aspistrategist.org.au/is-china-readyto-resume-its-imperial-glory/>, Accessed 05/01/2017 16:15

G. Allison, R. D. Blackwill, A. Wyne (2013). Lý Quang Diệu bàn về Trung Quốc, Hoa Kỳ và thế giới. Hà Nội: Nhà xuất bản Thế giới.

George Koo (2016). How Donald Trump can make America great again. Available through $<$ http://www.atimes.com/donald-trumpcan-make-american-great/ $>, \quad$ Accessed 06/01/2017 16:40

Gideon Rose (1998). Neoclassical Realism and Theories of Foreign Policy, World Politics, Vol.51, No.1, 144-172

Helen V. Milner (2009).Power, Interdependence, and Nonstate Actors in World Politics: Research Frontiers.Princeton, NJ: Princeton University Press, 3-27

Jakobson, Manuel (2016). Foreign Policy Decisions Made in China. Asia\& the Pacific Policy Sudies, Vol.3, No.1, 101-110

James D. Fearon (1998). Domestic Politics, Foreign Policy, and Theories of International Relation. Annual Reviews. Polit. Sci Vol.1998, No.1, 289-313

Jeffrey Wasserstrom (2015). Here's Why Xi Jinping's 'Chinese Dream'Differs Radically From the American Dream. Available through < $<$ ttp://time.com/4077693/chinesedream-xi-jinping/>, Accessed 08/01/2017 $15: 35$

Jim O’Neill (2015). Making Space for China. Available through $<$ https://www. project-syndicate.org/commentary/ china-global-governance-by-jim-o-neill- 2015-03?barrier=accessreg $>, \quad$ Accessed 10/01/2017 15:40

Justin Vaisse (2016). Trump's International System: A Speculatie Interpretation. Available through $<$ https://warontherocks. com/2016/12/trumps-international-systema-speculative-interpretation/>, Accessed 20/01/2017 13:40

Latika Bourke (2016). Donald Trump has no experience in international diplomacy says Kevin Rudd. Available through $<\mathrm{http}$ ://www.smh.com.au/world/ donald-trump-has-no-experience-ininternational-diplomacy-says-kevinrudd-20161206-gt5gnd.html>, Accessed 22/01/2017 17:40

Laura Koran, Ryan Browne (2016). Can Trump be the first to go directly from corner office to Oval Office? Available through <http:// edition.cnn.com/2016/08/11/politics/donaldtrump-businessmen-presidents-history/>, Accessed 19/01/2017 11:40

Linda Jakobson, Ryan Manuel (2016). How are Foreign Policy Decisions Made in China? Asia\&The Pacific Policy Studies, Vol.3, No.1, 104

Mark Leonard (2013). Why Convergence Breeds Conflict. Available through <https:// www.foreignaffairs.com/articles/unitedstates/2013-08-12/why-convergence-breedsconflict $>$, Accessed 21/01/2017 8:15

Merriden Varrall(2015). Chinese WorldViews and China's Foreign Policy. Sydney, Australia: Lowy Institute

Nick Penzenstadler and John Kelly (2017). How 75 pending law suits could distract a Donald Trump presidency. Available through $<\mathrm{http}$ // www.usatoday.com/story/news/politics/ elections/2016/10/25/pending-lawsuitsdonald-trump-presidency/92666382/>, Accessed 25/01/2017 8:22

Prashanth Parameswaran (2016). What Will Donald Trump's Asia Policy Look Like? Available 
through <http://thediplomat.com/2016/11/ what-will-donald-trumps-asia-policy-looklike/>, Accessed 17/01/2017 8:12

Rod Lyon (2015). America's Real Problem in Asia: Beware of the 'Assurance' Dilemma. Available through <http:// nationalinterest.org/blog/the-buzz/americasreal-problem-asia-beware-the-assurancedilemma-13856>, Accessed 25/01/2017 9:45

Susan (2008). China: Fragile Superpower ( $1^{\text {th }}$ ed). Oxford: Oxford University Press

Robert Keohane, Joseph Nye(2001). Power and Interdependence ( $\left.3^{\text {th }} \mathrm{ed}\right)$. New York, NY: Longman

Thomas R. Pickering (2000). The changing Dynamics of U.S Foreign Policy-Making. U.S Foreign Policy Agenda, Vol.5, No.1, 5-8

Zachary Crockett (2017). Donald Trump is the only US president ever with no political or military experience. Available through $<$ http://www.vox.com/policy-andpolitics/2016/11/11/13587532/donald-trumpno-experience>, Accessed 12/01/2017 11:30

China Capital Outflows Rise to Estimated \$1 Trillion in 2015 (2016). Available through $<$ https://www.bloomberg.com/news/ articles/2016-01-25/china-capital-outflowsclimb-to-estimated-1-trillion-in-2015>, Accessed 15/01/2017 15:49

Forbes 400 (2016). Available through $<\mathrm{http}: /$ www.forbes.com/profile/donaldtrump/?list=forbes-400>, Accessed 18/01/2017 15:20
Transcript: Donald Trump's Victory Speech. Available through <https://www.nytimes. com/2016/11/10/us/politics/trumpspeech-transcript.html?_r=2>, Accessed 26/01/2017 9:17

US-China ties will shape much of 21st century: John Kerry. Available through $<$ http://www. straitstimes.com/world/united-states/uschina-ties-will-shape-much-of-21st-centuryjohn-kerry>, Accessed 24/01/2017 11:14

With his call to put "America First", Donald Trump is the latest recruit to a dangerous nationalism. Available through $<\mathrm{http}$ ://www. economist.com/news/leaders/21710249-hiscall-put-america-first-donald-trump-latestrecruit-dangerous>, Accessed 19/01/2017 11:00

\section{Tiếng Trung Quốc}

国家统计局关于 2015 年国内生产总值 (GDP)

最终核实的公告. Available through $<$ http://www.stats.gov.cn/tjgz/tzgb/201701/ t20170109_1451239.html>, Accessed 14/01/2017 9:50

剪不断理还乱 李光耀的中国情结. Available through <http://www.bbc.com/zhongwen/ simp/indepth/2015/03/150318_liguangyao_ china $>$, Accessed 07/01/2017 10:47

习近平同志简历. Available through <http://cpc. people.com.cn/GB/64192/105996/6463136. html>, Accessed 12/01/2017 8:33

中国国务院新闻办公室, 中共中央文献研究 室, 外文出版社发行事业局 (2014). 《习近 平谈治国理政》. 北京: 外文出版社 


\title{
US-CHINA RELATIONSHIP UNDER THE TRUMP'S ADMINISTRATION
}

\author{
Nguyen Ngoc Anh \\ Center of Linguistics and International Studies, VNU University of Languages and International \\ Studies, Pham Van Dong, Cau Giay, Hanoi, Vietnam
}

\begin{abstract}
The article first highlights the international context and introduces international reseachers' predictions about the relationship of the US and China after Donald Trump was elected the 45th president of the United States. Secondly, with reference to theories of foreign policy analysis, this article analyzes the predictions. Finally, the article predicts that the relationship of the US and China under the Trump's administration will become tenser, but no conflict will happen. The article argues that all countries must put their national interests above all else. In the relationship of the US and China, tension will protect the national interests, but conflict will harm them.
\end{abstract}

Keywords: relationship, US, China, Donald Trump, Xi Jinping 